Western University

Scholarship@Western

Philosophy Publications

Philosophy Department

2015

\title{
Can a Right to Reproduce Justify the Status Quo on Parental Licensing?
}

Andrew Botterell

University of Western Ontario, abottere@uwo.ca

Carolyn McLeod

Western University, cmcleod2@uwo.ca

Follow this and additional works at: https://ir.lib.uwo.ca/philosophypub

Part of the Philosophy Commons

Citation of this paper:

Botterell, Andrew and McLeod, Carolyn, "Can a Right to Reproduce Justify the Status Quo on Parental Licensing?" (2015). Philosophy Publications. 475.

https://ir.lib.uwo.ca/philosophypub/475 


\title{
Can a Right to Reproduce Justify the Status Quo on Parental Licensing?
}

\author{
Andrew Botterell and Carolyn McLeod
}

\begin{abstract}
Most Western jurisdictions require parental licensing in the case of adoption but not in the case of assisted or unassisted biological reproduction. In an earlier paper, we set out to show that no arguments in favour of such a system of parental licensing succeed. One argument that we failed to consider, however, is one that appeals to the notion of a right to reproduce. According to this argument, prospective biological parents are protected from parental licensing because they exercise a right to reproduce when attempting to have children, while the same cannot be said about prospective adoptive parents. This paper shows that such an argument is flawed. It also questions whether people have a right to reproduce, and distinguishes this right from other, legitimate, rights, such a right to become a parent and a right to bodily autonomy.
\end{abstract}

\section{Introduction}

What is the normative status of the current system of licensing parents, according to which adoptive parents, and adoptive parents alone, are subject to parental licensing requirements? ${ }^{1}$ How successful, in particular, is the following argument in favour of this system: since people have a right to reproduce, licensing people who want to reproduce (with or without assistance from others) is not morally justified; but prospective adoptive parents do not exercise this right when they have children, and so licensing them is morally justified? This paper focuses on this argument and shows that it fails, primarily because the right to reproduce does not allow one to draw the distinctions that must be drawn if the current system of licensing parents is to be justified. We conclude that arguments based on the right to reproduce cannot support this system. Since we demonstrated in an earlier paper that arguments based on other purported differences between adoptive and non-adoptive

\footnotetext{
1 'Parents' here refers to legal parents. Foster parents are also licensed. Much of what we say in this paper about adoptive parents applies equally to foster parents.
} 
parenting do not support this system either (McLeod and Botterell forthcoming), we conclude more generally that the system is morally unjustified.

We spend a good deal of time in this paper discussing the nature and content of the right to reproduce. Although frequent appeals to this right are made in discussions concerning parental rights, children's rights, and other rights and obligations that have to do with the creation and parenting of children, it remains unclear what the right to reproduce amounts to. Is it equivalent to the right to pass on one's genetic material? Is it distinct from the right to become a parent? Does appeal to the right to reproduce add anything to appeals to the right to bodily autonomy? These questions require answers because the nature and content of the right to reproduce have important implications for how we assess the morality of begetting, bearing, and rearing children —in Onora O'Neill's evocative phrase — as well as for whether parental licensing is morally justified. ${ }^{2}$

\section{Background}

Our previous paper on parental licensing focused on the moral status of what we deemed the status quo, according to which adoptive parents are subject to parental licensing requirements that other parents are not subject to. What follows is an explanation of what we mean by 'parenting licensing' and a brief summary of our previous paper, in which we challenged the status quo.

When we refer to parental licensing, we have in mind, at a minimum, restrictions on the freedom to parent a child imposed by the state on people who may never have mistreated

\footnotetext{
${ }^{2}$ See O’Neill 1979.
} 
children. ${ }^{3}$ The state requires that these people show some competency in being a parent before they become one in a social sense. The relevant restrictions are prospective in this sense (although, as we acknowledge in our previous paper, they could be retrospective in the same sense). Adoptive parents tend not to receive an actual license to parent (similar to a driver's license); still, what they undergo is parental licensing. They are prevented from becoming parents unless or until they complete a home study, which consists of background checks on the financial, medical, and family histories of individuals, an evaluation of how child-friendly their home is, etc. Some prospective adoptive parents also attend mandatory parenting classes and must promise to submit periodic reports to governmental and/or private adoption agencies after they have adopted a child.

To be sure, the state sometimes interferes with the ability of non-adoptive parents to care for their children, though normally it does so retrospectively and not in a way that involves licensing. The state seeks to determine in such cases whether parents are mistreating their children, not whether they will mistreat them and should not be parents for this reason. Moreover, the state usually intervenes in this way only when there is evidence of severe parental incompetence, whereas prospective adoptive parents have to show a relatively high level of competence before they can become parents.

In summary, individuals wishing to become adoptive parents face licensing requirements that typically involve extensive (and often expensive) background checks and sometimes include mandatory educational programs. Moreover, these requirements tend to be unique to adoptive parents. Individuals who become parents by the traditional route or

\footnotetext{
${ }^{3}$ As Hugh LaFollette notes, parental licensing, like all licensing, involves "prior restraint": as he puts it, "a parental licensing program would deny licenses to applicants judged to be incompetent even though they had never maltreated children." (LaFollette 1980, 188) Similarly, we deny licenses to drive cars to people who have never caused an accident. One has to show some competency in the area before being licensed.
} 
with the use of assisted reproductive technologies (ARTs) are not normally subject to the same-or indeed any-restrictions. The question with which we were concerned in our previous paper was therefore this: Is the status quo with respect to parental licensing morally justified?" Our answer to this question was "no."

We arrived at this negative conclusion via a negative route. We considered a number of arguments - the best that we could find in the literature and also develop on our own - in support of the status quo on parental licensing. And we endeavoured to show that none of these arguments is any good. ${ }^{5}$ Our contention was not that parental licensing is morally justified or unjustified, ${ }^{6}$ but merely that the status quo on licensing could not be morally justified. Thus, our goal was simply to highlight what we took to be a fundamentally unfair situation in which adoptive parents are treated very differently than other parents. So much by way of background.

\section{The Right to Reproduce Argument}

In discussing the status quo on parental licensing, however, there was one objection to which we paid insufficient attention in our previous paper. According to this objection, the reason why non-adoptive parents should be free of any licensing is two-fold: first, because such parents (or prospective parents) have a right to reproduce; and second, because licensing requirements would unjustifiably interfere with that right. Support for this general argument can be found in the work of Christine Overall. Overall observes that as a matter of fact

\footnotetext{
${ }^{4}$ To be clear, not every form of adoption involves parental licensing; the status quo singles out a certain kind of adoption - non-family member adoption - for such licensing. In this paper, we ignore this complexity, along with other complexities with the status quo; for discussion see our other paper.

${ }^{5}$ See the section, "The Arguments in Favour of Licensing Adoptive Parents," McLeod and Botterell forthcoming.

${ }^{6}$ For discussion see in particular LaFollette 1980 and the papers collected in Tittle 2004.
} 
"individuals who do not seek [medical] reproductive services are not subjected to any test or qualification for parenting" and then notes that "if there is no screening system for prospective parents who do not need reproductive services, it seems unjust to subject to screening those who have the misfortune of needing medical help [to conceive]." The reason why such screening would be unjust is, according to Overall, that "such a system would be a severe imposition on people's bodily freedom and autonomy" (2012, 23). Since, for her, there is an important relationship between people's (especially women's) bodily freedom and autonomy and their right to reproduce - the former helps to ground the latter-her more general point is that licensing requirements for individuals wishing to conceive using ARTs would unjustifiably interfere with their reproductive rights.

Opposition to the above line of argument can be found, on the other hand, in the work of Hugh LaFollette. ${ }^{7}$ LaFollette rejects the idea that a right to reproduce-or, as he calls it, a "right to have children"— could justify licensing only adoptive parents $(1980,186)$. Such a right does not preclude the licensing of biological parents, according to LaFollette, because having the right is conditional on being the sort of person who would not abuse or neglect children. In other words, for Lafollette, no one has a right to have children that they will abuse or neglect $(1980,187-8)$. We will return to the question of how to interpret a right to reproduce. Suffice it to say that LaFollette does not believe that such a right supports the status quo on parental licensing. However, while we agree with LaFollette's conclusion, our

\footnotetext{
${ }^{7}$ See LaFollette 1980 and 2010. In his 1980 paper, LaFollette gives a general argument in favour of parental licensing, which goes as follows: we are justified in licensing individuals who engage in an activity A if (i) A is potentially harmful to others, (ii) the performance of A requires a certain competence, and (iii) we have a moderately reliable procedure for determining the presence or absence of such competence in relation to A. This argument applies to activities such as driving a car, and also to many professions - such as being a doctor, lawyer, or airline pilot - all of which require that individuals receive a license before they are entitled to engage in these professions. But interestingly, according to LaFollette, the argument also applies to parents, because parenting a child meets conditions (i)-(iii) above.
} 
reasoning differs from his. Compared to him, we delve more deeply into what might ground a right to reproduce.

To recap: the argument based on the right to reproduce in favour of the status quo on parental licensing - what we will call the Right to Reproduce Argument - is composed of two claims. The first is that there is a right to reproduce. The second is that while licensing biological parents is inconsistent with that right, licensing adoptive parents is not inconsistent with it. These two claims will structure the discussion that follows. Our general argument takes the form of dilemma: either the right to reproduce is groundless and so of dubious coherence, or it cannot draw the needed distinction between adoptive and non-adoptive parents. We therefore conclude that a right to reproduce cannot justify the status quo on parental licensing.

\section{The Function of Rights: Interests and Choices}

Before we can assess the Right to Reproduce Argument, we need to say more about what the right to reproduce amounts to. This will involve saying something about what rights are; about how rights can be grounded or justified; and in particular, about what the right to reproduce includes and excludes.

At a minimum, to have a right is to have an entitlement. If I have a right then I am entitled to demand that others do or refrain from doing certain things. So, for example, if I own a piece of property, then I am entitled to prevent others from coming on to it, and that entitlement stems from my ownership rights. Similarly, my right to bodily autonomy entails that I get to determine the ends to which my body may be put, and so others may not touch me without my consent. It is tempting to conclude that rights must therefore serve a function, 
that they must $d o$ something for those who hold them. But what function might rights serve? Two answers have traditionally been given to this question.

On the one hand, some theorists claim that rights function to protect certain important interests; Joseph Raz is perhaps the most prominent modern exponent of this view. According to Raz, an interest is an aspect of a person's objective well being, and in order to ground a right, an interest must be "a sufficient reason for holding some other person(s) to be under a duty" $(1984,195)$. This view of rights has become known as the interest theory. In defense of it, Harry Brighouse and Adam Swift say that rights should be "moral constructs designed to protect interests, [because interests] are the truly fundamental moral considerations" (2006, $87 \mathrm{ftn} .13)$.

On the other hand, some theorists claim that rights function to give an individual control over what other individuals can do. According to H.L.A. Hart, rights make an individual a "small-scale sovereign" $(1982,183)$. On this view, rights-holders have the ability to require others to act in various ways; in exercising a right they also exercise authority, and can command obedience in others. This theory has become known as the choice or will theory, since according to it rights function to protect choices that flow from the exercise of one's will.

The interest and the choice theory both have their strengths. The choice theory, for example, is ideally structured to make sense of the normative link between having a right and being in a position to exercise control: to have a right is to have the authority to demand that others do or refrain from doing certain things. And the interest theory gives effect to the plausible idea that there is a connection between having a right and being better off as a result of having that right. For if rights protect interests, and if interests are the truly 
fundamental moral considerations, then having a right to $\phi$ ought to be preferable to not having a right to $\phi$, at least with respect to the content or object of that right.

But as Leif Wenar points out (2011), both the choice theory and the interest theory run into problems when viewed as general accounts of the nature of rights. We will briefly highlight two such problems. First, the choice theory has trouble accounting for the fact that some rights are innate and cannot be waived. Recall that on the choice theory, to have a right is to exercise authority or control over what someone else can do. The fact that I own my bicycle authorizes me to prevent others from using it. But by the same token, because I am the owner of the bicycle I can waive such rights of exclusion and allow others to use it, or even give it away to somebody else. In short, according to the choice theory it ought always to be possible to release others from duties that flow from one's rights. But some rightssuch as the right not to sell oneself into slavery — appear to be inalienable, and that makes trouble for the choice theory.

Turning to the interest theory, it too is problematic because it cannot make sense of us having strong interests in things without having a right to those things, nor can it make sense of us having a right to something without having any interest in that thing. With respect to the first sort of case, while a man might have a very strong interest in having the Ontario Lottery and Gaming Corporation pay his spouse for her winning lottery ticket, he has no right against the lottery that it perform that action. Only his spouse, who is the bearer of the winning ticket, has that right. This is an example of an interest without a right. With respect to the second sort of case, judges have the right to pronounce verdicts of guilt and impose punishment on individuals who have committed criminal offences. But in doing so, they are required to act in a disinterested and impartial manner. Thus, if a judge did have a strong 
interest in the outcome of a particular case, we would be inclined to say that she lacks a right to decide it. This is an example of a right without an interest. In sum, it would appear that the links between rights and interests, and between rights and choices, are more complicated than interest and choice theorists make them out to be. ${ }^{8}$

Similar sorts of considerations, both pro and con, also arise in the reproductive context. For example, there are reasons to think that the right to reproduce serves to protect interests. As Christine Overall argues, both the right to reproduce and the right not to reproduce are "grounded in general human interests; people need protection from compulsory procreation as much as (or perhaps even more than) they need protection from denied procreation" $(2012,32)$. One might also argue that even if, as a matter of fact, rights sometimes protect choices, the choices that people make in reproductive contexts deserve protection only if those choices reflect some more fundamental interest. On the other hand, an interest theory also faces challenges when applied to a right to reproduce. Thus, in discussing the relationship between the right to reproduce and the interest in rearing a child, Muireann Quigley argues that this interest cannot ground the right to reproduce given that the interest in rearing a child can vary over time, and between people (2010). For can it really be said that only at times when $\mathrm{X}$ has a strong interest in rearing a child does she have a right to

\footnotetext{
${ }^{8}$ Although we are for the purpose of this discussion treating interest theories and choice theories as distinct and exclusive accounts of the functions of rights, it should be acknowledged that hybrid theories are possible, according to which rights are grounded in both interests and choices. Samantha Brennan defends such a theory when she argues that, with respect to children, "children move gradually from having their rights primarily protect their interests to having their rights primarily protect their choices." (Brennan 2002, 63) She calls this a gradualist account of rights. For discussion, see again Brennan 2002, Brennan forthcoming, and Vallentyne 2003.

Likewise, within a choice theory it is possible to distinguish between different kinds of choices, as Hugh LaFollette does when he distinguishes descriptive autonomy - the volitional and intellectual abilities that render an individual capable of making autonomous choices - from normative autonomy - roughly, those considerations that entitle an individual to make certain choices for him or herself (LaFollette 1998). Applied to the case of children, LaFollette argues that even if children are not descriptively autonomous, they should nonetheless be granted (circumscribed) normative autonomy, from which it follows that various rights possessed by children can be grounded in this kind of choice.
} 
reproduce, or that if $\mathrm{X}$ has this interest but $\mathrm{Y}$ lacks it then $\mathrm{Y}$, unlike $\mathrm{X}$, has no right to reproduce? The strangeness of these results suggest that an interest in rearing a child, or any interest for that matter, cannot be what grounds the right to reproduce. At the very least, it suggests that the relationship between interests and the right to reproduce is less straightforward than an interest theory makes it out to be.

Parallel considerations arise when we consider the claim that the right to reproduce ought to be grounded in choices. In support of this idea, it might be noted that people very often choose to reproduce regardless of whether they have an objective interest in reproducing; perhaps, all things considered, their lives will go less well should they reproduce. Still, they might have a right to reproduce. In addition, one might insist that the right to reproduce is justified, in part at least, by people's bodily autonomy - that is, their ability to choose autonomously what they want to have happen to their bodies-which is violated when they are subject, for example, to forced abortion or forced sterilization. On the other hand, one might worry that if the right to reproduce is essentially a reproductive right, and if a right to bodily autonomy has no necessary connection to reproduction (a person can exercise this right in non-reproductive contexts), then the latter cannot, without more, ground the right to reproduce.

In short, while there are reasons to take both an interest theory and a choice theory of rights seriously when thinking about the right to reproduce, other considerations pull in the opposite direction. What is clear, however, is that —at least in the context of the Right to Reproduce Argument - the right to reproduce is a negative right. On this understanding, the right does not entitle its bearer to any particular means or outcome, but amounts to an entitlement not to be interfered with in procreation. According to the Right to Reproduce 
Argument, in other words, licensing non-adoptive parents is inconsistent with the right to reproduce because licensing interferes with one's ability to reproduce.

\section{Grounding a Right to Reproduce}

In summary, there are two dominant theories about the functions of rights, the choice theory and the interest theory. And there is the particular right with which we are presently concerned, namely the right to reproduce understood negatively as a right not to be interfered with in matters intimately connected with procreation. Consequently, if there is such a right it follows that - unless the right is sui generis - it must be grounded either in a fundamental interest or in a right to autonomy. Finally, recall that the reason we are interested in the right to reproduce is because it forms a core part of an argument in favour of the status quo on parental licensing, a state of affairs that we believe is fundamentally unfair.

Now let us explain why the Right to Reproduce Arguments fails. Our argument will proceed as follows. First, we will consider whether the right to reproduce can be grounded in a fundamental interest in genetic or biological reproduction, or in child rearing. Next, we will discuss whether this right can be explained in terms of a general right to bodily autonomy or in a particular right to procreative autonomy. We will argue that either the right to reproduce cannot be grounded in these interests or choices; or if it can, that it is incapable of underwriting a distinction between adoptive and non-adoptive parents that would support the status quo on parental licensing.

\subsection{Grounding the Right to Reproduce in Interests}


There are two broad categories of interests that could plausibly be said to ground a right to reproduce: interests having to do with creating children to which one is genetically or biologically related, and interests having to do with rearing children - that is, with becoming a parent.

\subsubsection{The Interest in Genetic or Biological Reproduction}

Presumably, many people value having offspring to which they are genetically related or, in the case of women, to which they are biologically related through gestation and possibly also through genetics. In other words, many people have an interest in being "begetters" or "bearers" of children. However, as various authors including O’Neill have argued, a mere interest in genetic or biological reproduction cannot ground a right to reproduce. ${ }^{9}$ For no one has a right to create a child without taking any responsibility for the rearing of it. Reproduction is valuable largely because of the opportunity it gives people to parent a child (i.e., to be "rearers"). A desire simply to reproduce is not sufficient to ground a right because, contrary to what John Robertson suggests, whether one reproduces or not could not be central to one's "dignity, and the meaning of one's life" (1994, 24). Surely we would not agree, for example, that what truly afforded a man dignity and imbued his life with meaning was the passing on of his genetic material. Hence, we would not accept a man's "claim to a right to the unfettered distribution of his sperm" (Quigley 2010, 406). Similarly, we would reject a woman's assertion that she has a right simply to experience pregnancy and childbirth given the consequences that typically, and as a matter of fact, follow such experiences. In short, while genetic reproduction or gestation is important when conjoined with the possibility of becoming a parent, an interest in doing either or both on their own is not

\footnotetext{
${ }^{9}$ See O’Neill 1979. See also Quigley 2010, Steinbock 1995, Pearson 2007, and Rulli unpublished manuscript.
} 
significant enough to ground a right to reproduce. ${ }^{10}$

But regardless of whether the right to reproduce just is a right to have genetic or biological offspring, the fact is that some non-adoptive parents have no genetic or biological connection to their children, which means the right to reproduce thus understood could not justify the status quo on parental licensing. For example, if a couple uses a gamete donor to conceive, the resulting child will bear no genetic relation to at least one of the parents and so the right to reproduce would not prohibit imposing on such couples (or at least on the nongenetic parent) licensing requirements. However, with the status quo, there is no licensing for these couples or individuals (at least so long as they are heterosexual). ${ }^{11}$ Similarly, there is no licensing in most jurisdictions for couples who use gamete donors and a contract pregnant woman to have a child, even though the resulting child will bear no biological connection to either parent, and so the right to reproduce understood as a right to have genetic or biological offspring could not protect either of them from licensing. In summary, the Right to Reproduce Argument fails on the above interpretation of a right to reproduce.

\subsubsection{The Interest in Rearing Children or in Parenting}

Another interest that could ground a right to reproduce is an interest in child-rearing or parenting. As noted above, some argue that the right to reproduce should be understood in terms of the value of becoming a parent.

\footnotetext{
${ }^{10}$ For more on the alleged value of passing on one's genes, see Levy and Lotz 2005, Overall 2012, and Rulli unpublished manuscript; on the value of experiencing pregnancy and childbirth, see Overall 2012 and Rulli unpublished manuscript. To be clear, we do not deny that pregnancy and childbirth can be valuable; we simply reject the view that an interest in having these experiences alone could ground a right to reproduce.

${ }^{11}$ We noted above that in this paper we would disregard certain complexities with the status quo on parental licensing. One of them is the licensing of the homosexual partner who is not genetically related to a child that the couple produces using ARTs. In some jurisdictions (e.g., many states in the United States), this individual has to adopt the child as a non-family member. For discussion, see Crawford forthcoming.
} 
According to Overall, an interest in having children, which is vital to many people, helps (along with women's "bodily freedom and autonomy"12) to explain a right to reproduce (2012, 20-1), although what makes having children worthwhile is the parent-child relationship (212). Thus, in her view, the interest that contributes to the justification of a right to reproduce is indeed an interest in parenting. In describing the parent-child relationship and its value, Overall refers to the "mutually enriching, mutually enhancing love that is [this] relationship" $(2012,217)$, the asymmetrical nature of this relationship $(2012,215)$, the opportunity it brings "for the growth of experience, the expansion of knowledge" or more generally for "self-transformation" (2012, 219), etc. In some ways, her discussion is reminiscent of Harry Brighouse and Adam Swift's argument in support of the idea that people have a right to parent (2006). ${ }^{13}$

Parenting can be very valuable, to be sure; however, grounding a right to reproduce in an interest in parenting is problematic because the satisfaction of this interest does not always require reproduction. The reason, of course, is that people can become parents and experience the unique value of parenting by, for example, adopting a child. Consequently, it is not clear that people have a right to reproduce simply in virtue of their interest in parenting. ${ }^{14}$ In other words, their right to parent does not necessarily amount to a right to

${ }^{12}$ We discuss the right to bodily autonomy below.

${ }^{13}$ Brighouse and Swift argue that many people have a fundamental interest in intimate relationships of a certain kind, and that only the relationship that obtains between a parent and his or her child can satisfy this interest. The reason lies in the unique characteristics of the parent-child relationship, which (i) is structurally unequal, given children's intrinsic vulnerability; (ii) is structured in a way that prevents children from exiting the relationship; (iii) is shaped by the particular ways in which children express their love for their parents, viz., spontaneously, unconditionally, and unreflectively; and (iv) puts parents in charge of their children's well-being and development.

${ }^{14}$ See de Wispelaere and Weinstock forthcoming. Granted, the opportunity to adopt a child can be limited or even nonexistent. The availability of children for adoption, both domestically and internationally, can be quite low. However, the low numbers and long waiting lists are, as Tina Rulli argues, an "artifact of adoption opposition" (Rulli forthcoming). In our view, they are an artifact more specifically of the greater value that our societies place on people's right to reproduce rather than children's right to have families. Taking the latter right 
reproduce. What grounds a right to parent-experiencing the challenges and joys of a parentchild relationship — cannot ground a right to reproduce when those experiences can be had without reproducing.

Explaining the right to reproduce in terms of an interest in parenting is also problematic in the context of this paper because, so understood, the right cannot justify the status quo on parental licensing. It does not allow us to draw the required distinction between adoptive and non-adoptive parents. For on this interpretation, the right to reproduce is really no different than a right to parent, which is a right that prospective adoptive parents have as much as other prospective parents do. In sum, if the right to reproduce is to support the status quo on parental licensing, then it needs a different moral basis.

Another interpretation of the right to reproduce based on an interest in parenting is possible, however. According to this view, the right to reproduce protects an interest not in parenting a child, but rather in parenting "one's own child," as many people put it; that is, one's biological child. Such a view is worth taking seriously for obvious reasons. If the right to reproduce is based in an interest in parenting one's biological child, then, given that the right, so understood, is not exercised by adoptive parents - their children, while their own, ${ }^{15}$ are not biologically related to them-it presumably could distinguish non-adoptive parents from adoptive parents and in turn justify the status quo on parental licensing.

But can the right to reproduce understood in terms of an interest in parenting one's "own"- that is, one's biological—child do the work we need it to do? We think that it cannot. First, and most obviously, given that there is a straightforward sense in which adoptive parents can legitimately say of their adopted children that they are "their children,"

seriously along with people's right to parent should silence some adoption opposition and free up for adoption more children who do not have parents.

${ }^{15}$ Rulli forthcoming and Overall forthcoming. 
the concept of a child of one's own is too thin to ground a right the absence of which is supposed to permit the state to interfere with the fundamental interests of adoptive parents in becoming parents.

Second, the reasons that have been offered in support of the idea that people have a vital interest in having a genetic or biological connection to their children simply could not ground a right to reproduce. For instance, the reasons people tend to give for why they need to be genetically related to their children are either implausible, reflecting a naïve understanding of genetics, or are too weak to support a right to reproduce. ${ }^{16} \mathrm{~A}$ reason that is commonly given is family resemblance: that is, wanting children with whom one shares various characteristics, which one might feel is important for bonding with one's children. However, underlying assumptions here about bonding and family resemblance are contentious. First, studies indicate that mother-child attachment is normally as strong as with adoption as it is with biological reproduction. ${ }^{17}$ Second, family resemblances are not as genetic as, and tend to be significantly more social than, people usually assume they are (Levy \& Lotz 2005). These resemblances are also normative, because they stem from a normative genetic conception of family, according to which family resemblances need to be genetic (Rulli manuscript, Witt 2005, Haslanger 2005). The connection between family resemblance and this conception of family may help to explain the social pressure siblings can feel where one of them is adopted to reveal this fact when people comment on how much they look alike as siblings. ${ }^{18}$

\footnotetext{
${ }^{16}$ Various authors defend this claim and we will not rehearse all of their arguments here. But see, e.g., Levy and Lotz 2005, Overall forthcoming, and Rulli unpublished manuscript.

${ }^{17}$ L. Singer et al 1985 and Koepke et al 1991. Thanks to Tina Rulli for these references. See also Fontenot 2007.

${ }^{18}$ Thanks to Joe Heath for this example.
} 
Similarly, reasons people might give in support of parenting their "own child," understood simply as a child they have given birth to, are unpersuasive. The idea that one needs to gestate and give birth to one's child, or participate in those experiences as someone's partner, in order to satisfy one's interest in parenting strikes us as prima facie wrong. What could support this view other than a commitment to the idea that parents who are biologically connected with their children are more naturally parents or are better parents than those who do not share such a biological connection? In response, one might argue that the act of gestation makes one more likely to parent well, at least in the absence of mandatory counseling or licensing. In particular, one might, like Anca Gheaus, believe that "[i]n spite of, and sometimes in virtue of, its tribulations, pregnancy ... helps prepare people for the dramatic change brought about by parenthood" $(2012,22)$. This point could support not only the right that Gheaus defends - namely the right to "parent one's biological baby"but also a right to reproduce. ${ }^{19}$ For if pregnancy prepares one for parenthood, and if one has an interest in parenting and parenting well, then that interest might ground a right to become pregnant and to gestate - that is, a right to reproduce.

However, even assuming that Gheaus's claim about pregnancy is true, it does not show that pregnancy is uniquely preparatory in the way in which the Right to Reproduce Argument would require. For all that Gheaus argues the preparation involved in adopting a child could be just as beneficial as that of pregnancy, even if there were no mandatory counseling or licensing for adoption. Gheaus says it very well may be that "[b]earing parents have an advantage over adoptive parents" in terms of how ready they are for parenthood, and that the status quo on parental licensing is legitimate for this reason (although not this reason

\footnotetext{
${ }^{19}$ The two rights are different: the right to parent one's biological baby, as Gheaus understands it, allows people to "keep the babies that result from their own pregnancies," but not to endeavour to conceive those babies in the first place.
} 
alone $\left.^{20}\right)$. But this analysis ignores the tribulations that adoptive parents often experience that do not concern licensing. ${ }^{21}$ Examples include financial burdens, emotional burdens brought about by the fear that the adoption will never be complete or that one will lose a child to which one was matched, and the social burden associated with people questioning one's decision to adopt a child (because their friend did so and it was a disaster) or to pursue a particular kind (international vs. domestic, public vs. private) of adoption. Persisting with adoption in spite of, and even perhaps in virtue of, these difficulties arguably prepares people well for becoming an adoptive parent. Gheaus needs to show otherwise for her argument to succeed.

In summary, in our view the right to reproduce cannot be grounded in an interest in parenting "one's own," that is, one's biological child; and only in circumstances where adoption is not an option (or perhaps not a good option) can the right to reproduce be explained simply in terms of an interest in parenting. Again, one needs a different interpretation of a right to reproduce to make the Right to Reproduce Argument work.

\subsubsection{Other Interests}

Are there other interests that could be appealed to in an attempt to ground the right to reproduce? There are, though many of them are not plausible candidates, such as an interest in giving "the gift of life," fulfilling duties to family, or conforming to bionormative and

\footnotetext{
${ }^{20}$ She gives one further reason: "[i]f there is already a relationship between babies and bearing parents when babies are born, and this relationship is constitutive of adequate parenting, then there is less reason, other things being equal, to scrutinise both the parental entitlement and the parental adequacy of bearing parents than that of adoptive parents" $(2012,22)$. To respond, one would only be inclined to say that gestating and giving birth to a child is constitutive of adequate parenting if one already believed that biological parents have an entitlement to parent that adoptive parents lack. But given that that is precisely what is at issue, it cannot be assumed from the outset.

${ }^{21}$ To be clear, the tribulations brought on by licensing are not relevant here because whether adoptive parents should be licensed is what is at issue.
} 
pronatalist social ideals (on which see Overall forthcoming). However, there is one candidate that might seem promising: the interest people may have in avoiding some of the tribulations of adoption that are unique to it (or that seem to be, at any rate). These difficulties can include explaining to one's child why he is different from other children in not coming from his mommy's tummy, or why his birth parent(s) or family relinquished him for adoption; having to convince one's child that one is her "real" mom or dad; making tricky decisions about the birth family and one's child's present or future relationship with it; dealing with behavioural problems in one's child that stem from him being institutionalized for long periods of time or simply from being adopted; and navigating a racist society as a white parent of a child of a minority race.

While we in no way believe that the above challenges are trivial, we do want to say the following about them: (1) biological parents can face similar difficulties (that arise, e.g., because of divorce or behavioural problems in children that are not the result of either adoption or divorce); (2) the behavioural problems of adopted children tend to be exaggerated; in point of fact, "[t]he vast majority of children who are adopted are well within the normal range of well-being and show behavioural patterns that are similar to their nonadopted peers" (Blake et al forthcoming, citing Brand and Brinich 1999); (3) tackling some of the unique challenges of adoption, especially those that exist because of racism or the bionormative ideal of the family (see Witt forthcoming), is worthwhile and can be rewarding (Rulli forthcoming, Haslanger 2009); and (4) there is value for parents in adopting children that goes beyond fighting prejudice and include, most of all, enhancing a child's life prospects (see Blake et al forthcoming, and Rulli forthcoming). In short, the idea that people 
have, in effect, an interest in avoiding adoption is questionable. And if that is true, then such an interest cannot ground a right to create a child rather than have one via adoption.

\subsection{Grounding the Right to Reproduce in the Right to Autonomy}

If the interest theory is incapable of grounding a right to reproduce that draws the sort of distinction that would support the status quo on parental licensing, then perhaps the choice theory can do what the interest theory cannot. We turn now to this possibility, and analyze two categories of autonomous choice that seem relevant here. The first is bodily autonomy. And the second is procreative autonomy.

\subsubsection{Grounding the Right to Reproduce in Bodily Autonomy}

It is tempting to argue that the right to reproduce is simply a manifestation of the right to bodily autonomy, where bodily autonomy is interpreted as being "self-determining ... with respect to one's body" (and not simply as having the capacity for such self-determination, which is Overall's view $(2012)^{22}$ ). The right to bodily autonomy has been used most often to undergird women's right not to reproduce. As Overall argues, without the right to bodily autonomy, women are "little more than procreative slaves," because they will be made to reproduce against their will $(2012,21)$. But the right to bodily autonomy has also been invoked to support some women's and others' right to reproduce, and more specifically, not to be subject to such practices as forced abortion, forced sterilization, and forced contraception.

${ }^{22}$ For such an understanding of autonomy, see McLeod 2002. Overall uses the phrase "bodily freedom and autonomy" (2012). Moreover, she defines bodily freedom as "the absence of physical, legal, or social constraints on one's decisions about one's body" (21). Because we interpret bodily autonomy more broadly than Overall does and in a way that captures what is problematic about external constraints on our bodies, we do not need to refer to both bodily autonomy and freedom. 
We take it as given that with a right to bodily autonomy comes an entitlement not to be subject to the sort of practices just mentioned. Whether one needs to refer to a special right to reproduce to acknowledge this entitlement is questionable, however. For what is wrong with these practices insofar as they infringe on people's bodily autonomy is simply that they involve unwanted touching or violations of the body, not that they prevent people from reproducing. As noted above, the right to bodily autonomy has no necessary connection to reproduction, and that is true even when the right is invoked to oppose such horrors as forced sterilization.

But one might object that while there is no necessary connection between bodily autonomy and the right to reproduce, there is all the same a deeply intimate connection between a right to bodily autonomy and reproduction, particularly for groups of people that have been targeted by eugenics programs (e.g., people with disabilities and minority racial or ethnic groups). The state needs to acknowledge that such individuals have a right to reproduce, grounded in their right to bodily autonomy, if only for the political purpose of thwarting efforts to prevent them from reproducing in the future. However, we believe that in claiming that these people have a right to reproduce, one is insisting not simply that they should be self-determining with respect to their bodies, but also that their interest in reproducing or their choice to reproduce is as legitimate as anyone else's. This is to say that their right to reproduce is grounded in something more than a right to bodily autonomy. All the same, the right to reproduce so understood remains very narrow, amounting either to a negative right not to be subject to eugenics programs in the first place, or to a right exercisable by members of a group that has been the target of eugenics programs to engage in reproductive activities, free from state interference. Consequently, even if a right to 
reproduce is recognized in the context of eugenics programs, such a right remains restricted to such contexts; it cannot be appealed to more generally in support of the Right to Reproduce Argument.

In summary, without downplaying the obvious importance of a right to bodily autonomy, we are skeptical that it alone could ground a right to reproduce. But we also question whether the Right to Reproduce Argument in favour of the status quo on parental licensing would succeed even if the right to reproduce were understood in this way. Recall that according to this argument, the right to reproduce protects people from licensing who engage in assisted, not just unassisted, reproduction. But could the right serve this purpose if it basically amounted to a right to bodily autonomy? It would have to guarantee, not only that one should not be subject to unwanted touching by others (and thus not be subject to forced abortions and the like), but that, in addition, one should be subject to wanted touching by others (and thus to medical interventions to cure or bypass infertility). However, we find this interpretation of the right to bodily autonomy implausible. We are reminded here of Judith Thomson's discussion of a right to life (1971). Recall that according to Thomson, even if one needs Henry Fonda's cool hand on one's fevered brow in order to live, one does not have a right to it despite having a right to life. Similarly, a right to bodily autonomy does not entitle one to everything that one needs in order to exercise it, and so refusals by others to help one be self-determining with respect to one's body by engaging in assisted reproduction might be legitimate. In addition, some actions of others that inhibit such self-determination-including imposing licensing requirements — might be appropriate.

In short, although the right to reproduce understood in terms of a right to bodily autonomy would bar the state from having a licensing program that relies on measures such 
as forced abortion, it would not prevent the state from licensing all people who become parents via reproduction. In particular, it would not prevent it from licensing people who can only reproduce with assistance from others.

\subsubsection{Grounding the Right to Reproduce in Procreative Autonomy}

If a general right to bodily autonomy cannot ground the right to reproduce, then perhaps a more narrowly tailored right can. So consider the idea of explaining the right to reproduce in terms of the specific right to procreative autonomy. According to this view, certain choicessuch as voluntarily becoming pregnant, or carrying a fetus to term, or giving birth — are essentially procreative in nature. Although in making such choices individuals may exercise other, non-procreative abilities, the choices are nonetheless inextricably linked to procreation. But because they are linked to procreation — that is, to begetting and bearing children — and because adoptive parents do not exercise procreative autonomy when forming a family via adoption, a right to reproduce grounded in procreative autonomy can support the status quo on parental licensing. For this right distinguishes some choices - namely those of people who become parents via the exercise of procreative autonomy-from others - those of people who become parents via the exercise of non-procreative autonomy-and so justifies the differential treatment of these two groups with respect to parental licensing.

Unsurprisingly, we are of the view that the right to reproduce understood in this way cannot justify the status quo. First, it is not clear why procreative choices should be accorded the normative weight that this understanding gives them. Second, even if the right to reproduce served to protect procreative autonomy, not everyone's choice to become a nonadoptive parent is, in fact, an exercise of procreative autonomy and so the Right to 
Reproduce Argument would fail on this interpretation of the right. To see why, consider in particular the case of individuals who become parents using both donor gametes and contract pregnancy. It is very hard to view such individuals as exercising procreative autonomy since they are not procreating. To be sure, without their contributions and input a new life would not be created. But that cannot be sufficient for the exercise of procreative autonomy. For without the skill and help of the staff at an IVF clinic many couples would also be incapable of becoming parents. And it does not follow that the right of the staff to do what they do is grounded in, or is a manifestation of, their procreative autonomy. There is therefore a gap between playing an essential role in the process or act of procreation and exercising a right to procreative autonomy. There is also no clear difference between adoptive and non-adoptive parents in terms of whether the exercise of this right is what supports their choice to become parents. Consequently, the right cannot validate the Right to Reproduce Argument.

These observations lead to another possibility, however: namely that the right to procreative autonomy is at bottom the right to bring new people into existence. For whatever right adoptive parents exercise when they choose to become adoptive parents, it surely does not involve the bringing into existence of new children; rather, it involves assuming responsibility for children who already exist. So could it be that, in the end, the right to reproduce is the right to, quite simply, create life? And could that right be sufficient to justify the conclusion of the Right to Reproduce Argument? We think it could not. For it is by no means obvious that there is a right to create life, or that the right to reproduce is such a right. As we noted above in connection with an interest in genetic or biological reproduction, it is doubtful that a woman who gives birth to a child and then promptly abandons it can be said to be exercising a right to reproduce, even though she is bringing a new person into existence. 
But perhaps more importantly, it is simply not obvious that a right to reproduce understood as a right to bring new people into existence could justify the status quo on parental licensing. The reason is sometimes couples decide together to create a new life, even though one member of that couple must, in order to become a parent of the life thereby created, adopt the child. We have in mind here lesbian and gay couples (see Crawford forthcoming). Their case makes trouble for the claim that the exercise of a right to create new life is what distinguishes adoptive parents from non-adoptive parents. For if what is at issue is the exercise of a choice to create new life, and if that choice is exercised jointly by a couple, one member of whom must adopt the resulting child in order to become its legal parent, then it does not follow that in becoming parents, adoptive parents do not sometimes exercise the right to bring new life into existence - assuming, again, that such a right even exists.

\subsubsection{Grounding the Right to Reproduce in a Right to Beget Equally?}

Before concluding this section, let us consider one final application of the choice theory of rights. According to Muireann Quigley, in a liberal democratic society such as ours the right to reproduce is best viewed as being grounded in an equality of liberty. Reflecting on John Rawls's claim that we are each entitled to an equal right to liberty and on Ronald Dworkin's view that we are each owed "equal concern and respect," Quigley argues for what she calls the right to beget equally, understood as "the equal right of individuals to attempt to reproduce in a manner pursuant to their values" $(2009,410) .{ }^{23}$ Her discussion of Rawls and Dworkin leads her to conclude that so long as individuals "choose to have children," each individual 'ought to have an equal right to 'concern and respect' in the political decisions

${ }^{23}$ Her concern is with arguing in favour of public funding for ARTs. 
about the 'goods and opportunities' that a society has to offer regarding [having children]" (Quigley 2009, 410).

In many ways, Quigley's idea is attractive: that in thinking about what individuals are entitled to as a matter of reproductive justice their concerns ought to be given equal weight. Still, we doubt that equality of liberty could, alone, ground the right to reproduce. Moreover, the problem with appealing to equality of liberty in the present context should be obvious: the status quo on parental licensing is a clear example of an institutional arrangement in which the liberty of some-non-adoptive parents - is given more weight than the liberty of others-adoptive parents. To impose on some prospective parents onerous licensing requirements while exempting other prospective parents from those same conditions does not show "equal concern and respect in the political decisions that govern" access to various mechanisms by which individuals become parents. To the contrary, the right to reproduce understood as a right to beget equally surely entails that the status quo on parental licensing is unjustified.

\section{Conclusion}

We set out in this paper to expand on our earlier critique of the status quo on parental licensing by revealing the flaws in a particular argument in favour of it, an argument that we have called the 'Right to Reproduce Argument.' In doing so, however, we have leveled a critique against the very notion of a right to reproduce. Although we are open to there being a narrowly tailored right to reproduce that protects groups of people from being targeted by eugenics programs, we have argued that there is no general right to reproduce. Our reasoning was that none of the various interests or choices that in our opinion could ground such a right 
seems to be able to do the job. The options we considered included an interest in reproducing genetically or biologically; an interest in parenting simpliciter or in parenting one's biological child; a right to autonomy; a right to procreative autonomy; and a right to beget equally. The strongest among these candidates, in our view, is the interest simply in parenting. As we indicated, however, this interest can be satisfied through adoptive parenting and will only justify a right to reproduce when there are no children available for adoption. Thus, we conclude that the first horn of the dilemma that we aimed to prove at the outseteither there is no free-standing right to reproduce or, if there is, it cannot support the status quo on parental licensing - may very well be true, with the possible exception, again, of a narrow right to reproduce that concerns a resistance to eugenics. Regardless of whether one accepts this conclusion, however, one ought to conclude that the second horn of the dilemma is true. The upshot is that one ought to reject not only the Right to Reproduce Argument, but also regard with suspicion all arguments that rely on a general right to reproduce. 


\section{References}

Baylis, Françoise and Carolyn McLeod. Forthcoming. Family-Making: Contemporary Ethical Challenges. Oxford: Oxford UP.

Blake, Lucy, Martin Richards, and Susan Golombok. Forthcoming. "The Families of Assisted Reproduction and Adoption." In Baylis and McLeod, Family-Making.

Brand, Ann and Paul Brinich. 1999. "Behavior problems and mental health contacts in adopted, foster, and nonadopted children." Journal of Child Psychology and Psychiatry 40(8): 1221-1229.

Brennan, Samantha. 2002. “Children's Choices or Children's Interests: Which do their Rights Protect?" In The Moral and Political Status of Children, edited by David Archard and Colin Macleod. Oxford: Oxford UP.

---. "The Good of Childhood and Children's Rights." In Baylis and McLeod, Family-Making.

Brighouse, Harry and Adam Swift. 2006. "Parents' Rights and the Value of the Family." Ethics 117: 80-108.

Crawford, Julie. Forthcoming. "On Non-Biological Maternity, or 'My Daughter is Going to be a Father!'” In Baylis and McLeod, Family-Making.

De Wispelaere, Jurgen and Daniel Weinstock. Forthcoming. "State Regulation and Assisted Reproduction: Balancing the Interests of Parents and Children." In Baylis and McLeod, Family-Making.

Fontenot, Holly B. 2007. "Transition and Adaptation to Adoptive Motherhood," Journal of Obstetric, Gynecologic, and Neonatal Nursing, 36 (2): 175-82.

Gheaus, Anca. 2012. "The Right to Parent One's Biological Baby." Journal of Political Philosophy 20(4): 432-455.

Hart, H.L.A. 1982. Essays on Bentham: Studies in Jurisprudence and Political Theory. Oxford: Clarendon Press.

Haslanger, Sally and Charlotte Witt, eds. 2005. Adoption Matters: Philosophical and Feminist Essays. Ithaca: Cornell University Press.

Haslanger, Sally. 2005. "YYou Mixed? Racial Identity Without Racial Biology." In Haslanger and Witt, Adoption Matters: 265-89.

---. 2009. "Family, Ancestry and Self: What is the Moral Significance of Biological Ties?" Adoption and Culture 2(1): 91-122. 
Koepke, J., S, Anglin J. Austin, and J. Delesalle. 1991. "Becoming Parents: Feelings of Adoptive Mothers." Pediatric Nursing 17: 333-36.

LaFollette, Hugh. 1980. "Licensing Parents." Philosophy and Public Affairs 9(2): 182-197.

---. 1998. "Circumscribed Autonomy: Children, Care, and Custody." In Having and Raising Children, edited by Julia Bartkowiack and Uma Narayan. State College, PA: Penn State University Press, 137-151.

---. 2010. "Licensing Parents Revisited." Journal of Applied Philosophy 27(4): 327-343.

Levy, Neil and Mianna Lotz. 2005. "Reproductive Cloning and a (Kind of) Genetic Fallacy." Bioethics 19: 232-250.

McLeod, Carolyn. 2002. Self-Trust and Reproductive Autonomy. MIT Press.

McLeod, Carolyn and Andrew Botterell. Forthcoming. "Not For the Faint of Heart: Assessing the Status Quo on Adoption and Parental Licensing." In Baylis and McLeod, Family-Making.

O’Neill, Onora. 1979. "Begetting, Bearing, and Rearing.” In Having Children: Philosophical and Legal Reflections on Parenthood, edited by Onora O'Neill and William Ruddick. New York: Oxford University Press, 25-38.

Overall, Christine. 2012. Why Have Children? Cambridge, MA: MIT Press.

---. Forthcoming. "What is the Value of Procreation?" In Baylis and McLeod, FamilyMaking.

Pearson, Yvette. 2007. "Storks, Cabbage Patches, and the Right to Procreate." Bioethical Inquiry 4: 105-115.

Quigley, Muireann. 2010. “A Right to Reproduce?” Bioethics 24(8): 403-411.

Raz, Joseph. 1984. “On the Nature of Rights." Mind 93: 194-214.

Robertson, John. 1994. Children of Choice. Princeton, NJ: Princeton University Press.

Rulli, Tina. Forthcoming. "The Unique Value of Adoption." In Baylis and McLeod, FamilyMaking.

---. Unpublished manuscript. "Preferring a Genetically-Related Child."

Singer, L. D.M. Brodzinsky, D. Ramsay, M. Steir, \& E. Waters. 1985. "Mother-infant attachment in adoptive families," Child Development 56: 1543-1551. 
Steinbock, Bonnie. 1995. "A Philosopher Looks at Assisted Reproduction." Journal of Assisted Reproductive Genetics 12(8): 543-551.

Thomson, Judith. 1971. "A Defense of Abortion." Philosophy and Public Affairs 1(1): 47-66.

Tittle, Peggy. 2004. Should Parents Be Licensed? Amherst, MA: Prometheus Books.

Vallentyne, Peter. 2003. "The Rights and Duties of Childrearing." William and Mary Bill of Rights Journal 11(3): 991-1009.

Wenar, Leif. 2011. "Rights." In The Stanford Encyclopedia of Philosophy, edited by Edward Zalta. URL $=<$ http://plato.stanford.edu/archives/fall2011/entries/rights/ $>$.

Witt, Charlotte. 2005. "Family Resemblances: Adoption, Personal Identity, and Genetic Essentialism.” In Haslanger and Witt, Adoption Matters: 135-44.

---. Forthcoming. "A Critique of the Bionormative Concept of the Family." In Baylis and McLeod, Family-Making. 